\title{
Post-attack Aposematic Display in Prey Facilitates Predator Avoidance Learning
}

\author{
Changku Kang ${ }^{1,2}$, Hyun-Joon Cho ${ }^{1}$, Sang-Im Lee ${ }^{1,3}$ and Piotr G. Jablonski ${ }^{1,4 *}$ \\ ${ }^{1}$ School of Biological Sciences, Seoul National University, Seoul, South Korea, ${ }^{2}$ Department of Biology, Carleton University, \\ Ottawa, ON, Canada, ${ }^{3}$ Institute of Advanced Machinery and Design, Seoul National University, Seoul, South Korea, \\ ${ }^{4}$ Museum and Institutue of Zoology, Polish Academy of Sciences, Warsaw, Poland
}

\section{OPEN ACCESS}

Edited by:

James A. R. Marshall,

University of Sheffield, UK

Reviewed by:

Jérôme Casas,

University of Tours/Centre National de la Recherche Scientifique, France Nicola Marples,

Trinity College Dublin, Ireland

${ }^{*}$ Correspondence:

Piotr G. Jablonski

snulbee@behecolpiotrsangim.org

Specialty section:

This article was submitted to

Behavioral and Evolutionary Ecology,

a section of the journal

Frontiers in Ecology and Evolution

Received: 18 February 2016 Accepted: 27 March 2016

Published: 14 April 2016

Citation:

Kang C, Cho H-J, Lee S-I and

Jablonski PG (2016) Post-attack

Aposematic Display in Prey Facilitates

Predator Avoidance Learning.

Front. Ecol. Evol. 4:35.

doi: 10.3389/fevo.2016.00035
Warning signals protect unpalatable prey from predation because predators who learn the association between the warning signal and prey unprofitability decrease attacks on the prey. Most of the research have focused on visual aposematic signals that are constantly presented and visible to the predators. But a variety of chemically defended insects are rather cryptic when resting, and only in response to predator attacks (post-attack) they perform displays of conspicuous abdomens or hindwings normally hidden under forewings. The function of those displays in unpalatable insects is not well understood. We examined two adaptive hypotheses on this facultative aposematic display using wild-caught oriental tits (Parus minor) as predators. First, we tested whether the display increases the rejection of the prey by predators upon seeing the display (i.e., at the moment of attack) through learning trials (aposematic signaling hypothesis). Second, we tested whether the display facilitates the memory formation between cryptic visible form of the prey and prey defense so that it prevents the predators initiate an attack upon seeing the cryptic form (facilitation hypothesis). We found that predators learned to avoid attacking the prey which supports the facilitation hypothesis. However, the support for the aposematic signaling hypothesis was equivocal. Our results open new directions of research by highlighting the possibility that similar facilitation effects may contribute to the evolution of various forms of post-attack visual displays in chemically, or otherwise, defended animals.

Keywords: aposematism, camouflage, crypsis, deimatic display, startle display, warning signals, coloration

\section{INTRODUCTION}

Aposematism comprises a situation when defended prey advertise their unpalatability to the predators by using conspicuous warning signals. Warning signals protect aposematic prey from predation mainly by facilitating predator learning to avoid the aposematic prey (Ruxton et al., 2004; Stevens and Ruxton, 2012). As an outcome of decades of research on visual aposematic signals we currently understand relatively well the mechanisms involved in the avoidance learning processes. The properties of the color signals that cause enhanced avoidance learning in predators include their high contrast against background (Osorio et al., 1999; Gamberale-Stille, 2001; Aronsson and Gamberale-Stille, 2009), novelty to the predators (Mappes and Alatalo, 1997), distinctiveness relative to the non-aposematic prey (Merilaita and Ruxton, 2007), or the color itself (Gaberale-Stille and Guilford, 2003). Many of the learning effects of various aposematic features are consistent with 
the classical psychology of learning, particularly with the idea that more salient stimuli cause faster associative learning (Mackintosh, 1983).

Predator susceptibility to the prey defense is crucial for avoidance learning processes of predators. However, some predators can attack and consume defended prey regardless of the prey defenses either because they are resistant to prey defense (Brodie and Brodie, 1999; Exnerová et al., 2003), they are either naïve or adventurous (Marples et al., 1998; Exnerová et al., 2010), or in circumstances when predators are in good body conditions and can endure the toxic chemicals of the prey (Skelhorn and Rowe, 2007; Barnett et al., 2012). Because of this inter/intraspecific variation in predator susceptibility to prey defense, a prey cannot entirely avoid the risk of being attacked or killed. Therefore, although defended prey can gain many advantages from being conspicuous, they rarely maximize their conspicuousness (Endler and Mappes, 2004).

One of the predator avoidance strategies of defended prey that has been poorly studied is represented by chemically defended prey that are rather cryptic when resting, but in response to predator attacks they display conspicuous body parts that are normally hidden (called "deimatic display"; Nickle and Castner, 1995; Kang et al., 2011; Umbers and Mappes, 2015). The benefit of having cryptic appearance is clear: it decreases the probability of detection by the non-susceptible predators that may be able to eat the defended prey. However, the mechanism by which the post-attack display of the hidden aposematic signal protects the distasteful prey has not been explored yet.

Aposematic prey usually constantly show conspicuous colors, which dissuade predators from attacking the prey upon seeing the conspicuous colors (Mappes et al., 2005). In the case of post-attack aposematic signals, the conspicuous warning colors are shown only after being attacked. Therefore, in accordance with the current evidence on predator avoidance learning (Gittleman and Harvey, 1980), we predict that predators may learn to associate the post-attack conspicuous display with prey distastefulness, leading to predators abandoning the prey after seeing the post-attack display (aposematic signaling hypothesis: Figure 1). Hence, aposematic signaling hypothesis predicts that the probability of the predator dropping the prey (after an attack) should increase as the predator repeatedly experiences more of those prey. In this hypothesis, the prey would gain survival advantages by avoiding fatal predatory handling after an initial attack. However, the aposematic signaling hypothesis does not predict the decrease in the initial attacks by educated predators because it is the post-attack display that reminds the predators about the prey defense.

Additionally, based on the psychological mechanisms of facilitation of learning (potentiation and augmentation which comprise one stimulus facilitating faster association between unpalatability and the second stimulus; Rusiniak et al., 1979; Batsell et al., 2001; Urcelay and Miller, 2009), we hypothesized that the post-attack display may facilitate the associative learning between the relatively non-conspicuous appearance of the resting prey and prey distastefulness (the blue arrow in Figure 1). Hence, the facilitation hypothesis predicts that predators will decrease their initial attacking attempts upon seeing the non-conspicuous

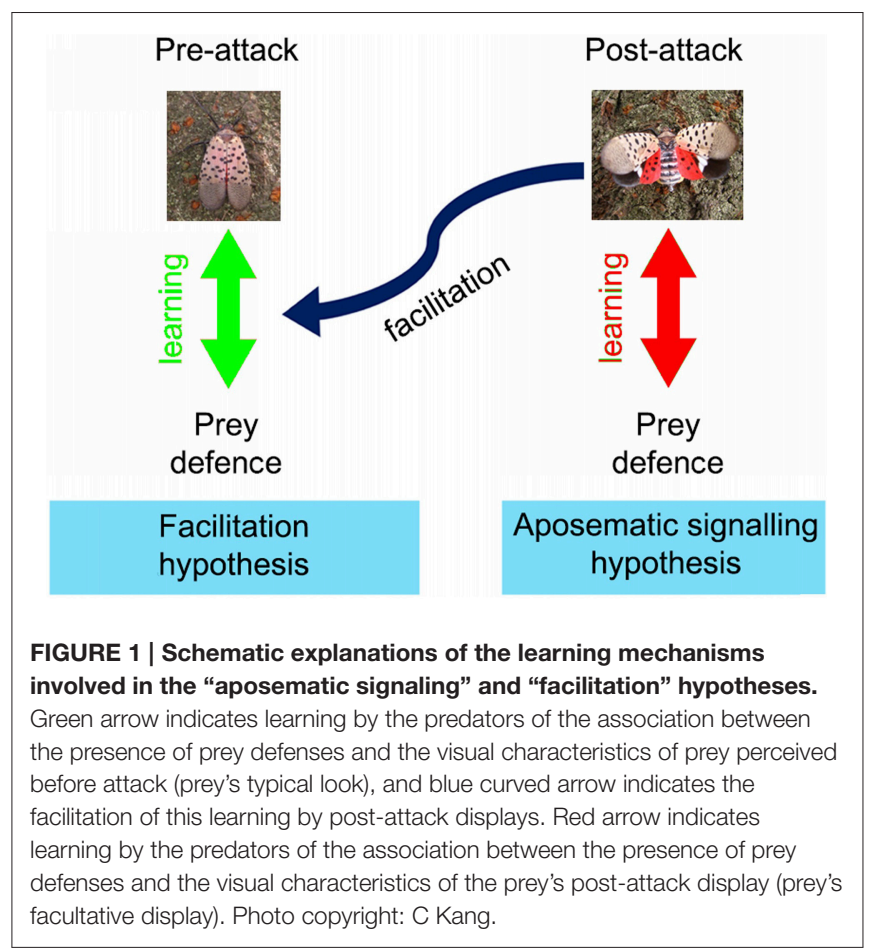

features of the prey as they experience more of those prey. In this hypothesis, the prey will benefit by preventing initial attacks by predators.

Here, we tested these two non-mutually exclusive hypotheses using avoidance learning trials of avian predators with artificial prey models. We specifically tested how the post-attack display in distasteful prey affects (1) the probability of abandoning the prey after seeing the display (aposematic signaling hypothesis), and (2) the frequency of initial attacks by predators (facilitation hypothesis) as the predators experience more of those prey. Then we compared the avoidance learning speed of predators on distasteful post-attack displaying prey with constantly nonconspicuous and constantly conspicuous distasteful prey.

\section{MATERIALS AND METHODS}

\section{Avian Predators and Experimental Arena}

We used the Oriental tit (Parus minor), which is a common insectivorous bird that can be found in most woodland areas in East Asia, as a general avian predator. Wild oriental tits $(P$. minor) were caught using mist nets in the forest nearby the Seoul National University campus (Mt. Gwanak, South Korea, N37 ${ }^{\circ} 5^{\prime}$; E126 $94^{\prime}$ ) between December 2011 and February 2012. They were housed individually in outdoor compartments $(90 \times$ $90 \times 170 \mathrm{~cm}$, covered by wire mesh walls) in which all experiments were carried out. Catching, housing of birds, and the experimental procedures were approved by Seoul National University Institutional Animal Care and Use Committees (SNUIACUC permission number: SNU-130621-6) in accordance with the approved guidelines. They were kept in natural lighting condition (through transparent plastic sheets on the roof) and temperature. We covered the walls between compartments with 
white curtains to prevent visual interactions between the birds and set several perches in each compartment. We provided sunflower seeds, butter, mealworms ad libitum with fresh water except during training and testing. On day 1-2 (day 1 indicates the day that birds were caught), we acclimatized the birds to their compartments. On day 3-4, we trained the birds to forage on the experimental feeder (see Training Section). On day 5-7, we performed the learning trials and released the birds back to the wild on day 8 . Total 36 birds were captured and tested.

\section{Artificial Prey Models and Experimental Feeders}

Prey items were divided into two classes: distasteful "defended" prey and edible "undefended" prey. For defended prey, we developed artificial prey models to mimic three kinds of insect prey: non-conspicuously colored prey (N-CONS), conspicuously colored prey (CONS), and non-conspicuously colored prey with a hidden conspicuous hindwing part that is facultatively displayed at the moment of predator attack (hereafter, called facultatively conspicuous prey; F-CONS). For each individual bird, only one type of defended prey (either N-CONS, CONS, or F-CONS), with the same color, was used as defended prey model in every trial (see Section Learning Trials). All three types of defended prey had a triangular forewing part $(2.5 \times$ $4.8 \mathrm{~cm}$; height and base respectively; Figure 2A). F-CONS prey had additional hindwing part with the surface area similar to the surface area of the front wings $(2 \times 4 \times 1.5 \mathrm{~cm}$; upper, lower bases and height) attached at the bottom of the forewing part. It was hidden from view until a bird started handling the prey (Figure 2B). Both N-CONS and CONS prey had a small piece of paper part $(1 \times 1 \mathrm{~cm})$ behind a forewing part which was used to attach the prey to the feeder (Figure 2A the rightmost photo). On the underside of each prey item, we glued one half of a sunflower which was prepared by soaking in $2 \%$ Bitrex solution for $24 \mathrm{~h}$. Bitrex is a non-toxic bitter tasting chemical with no perceptible odor which has been known to induce aversive reaction of birds after tasting (Skelhorn and Rowe, 2007). The undefended prey items were prepared in a similar way to N-CONS prey with an exception that the sunflower seeds were soaked in distilled water instead of Bitrex solution to make the undefended prey edible.

We used a flat square Styrofoam plate $(50 \times 50 \mathrm{~cm})$ as the experimental feeder on which prey items were presented (Figure 2C). We covered the plate with a brown-tone kraft paper and made 16 knife-cuts (about $5 \mathrm{~cm}$ for each) in the kraft paper. We fixed each prey by inserting the hindwing part of the prey into each cut. When the prey were fixed in this manner to the feeder, each prey only presented its forewing part, while the hindwing part (if present) was hidden beneath the kraft paper unless a bird pulled out the prey item. Each feeder contained 16 prey items presented in a $4 \times 4$ matrix with randomly assigned eight defended and eight undefended prey (see Learning Trials Section).

\section{Choice of Colors}

In order to be able to generalize our results across a range of conspicuous and non-conspicuous colors, we made a color "pool" which consisted of a variety of colors. For the conspicuous colors we chose either yellow, orange, or red which are often present in aposematic animals (Figure S1 for spectrometry). For the non-conspicuous colors we chose green, light brown, dark brown, light gray, dark gray, all of which are commonly found in camouflaged arthropod prey. The conspicuous colors

A
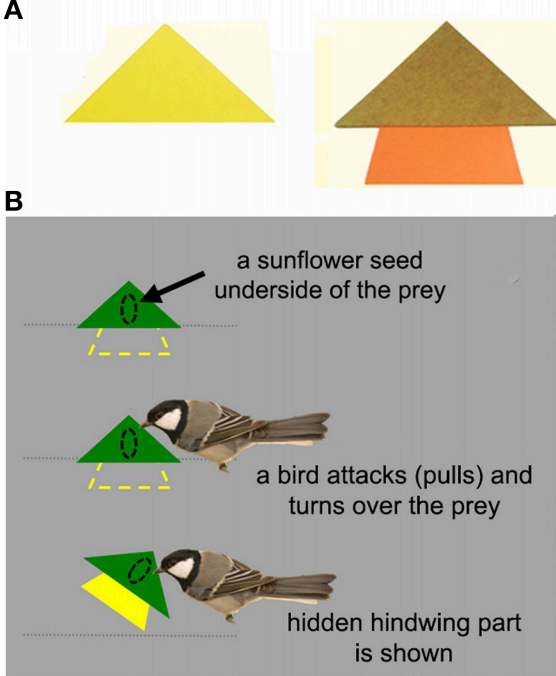
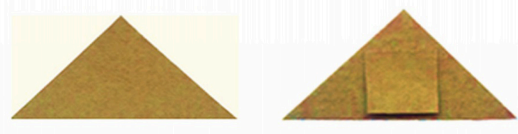

C

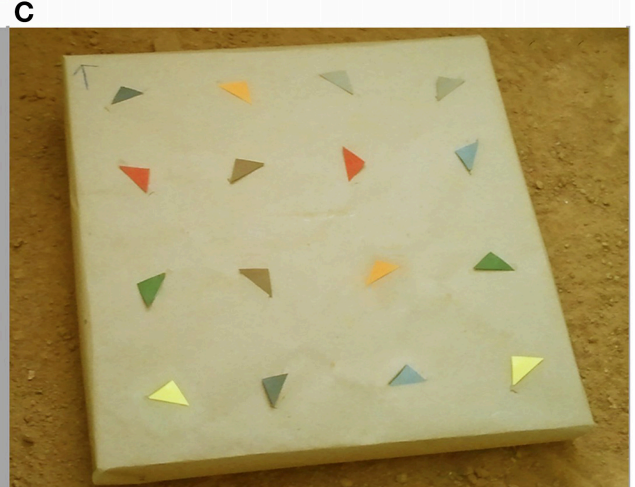

FIGURE 2 | Experimental feeder with prey models. (A) Examples of prey models used in the study. From left to right, continuously conspicuous prey (CONS; yellow), facultatively conspicuous prey (F-CONS; brown with hidden orange color), non-conspicuous prey (N-CONS; brown), and the reverse side of N-CONS prey which shows the small hindwing part that was used only for fixing the prey into the background. (B) The mechanism of how the "hidden" hindwing part was exhibited to the birds: hindwing part of the prey was inserted through a slit in the gray paper (representing the background) and therefore it was hidden from view until the bird pulled out the prey off the feeder. (C) An example of the experimental feeder with 16 prey items fixed. 
were clearly distinctive from the non-conspicuous colors and had higher contrast against the background than the non-conspicuous colors (judged from spectrophotometry; Figure S1). Each color was chosen based on the human visible range of light spectrum (400-700 nm). Although we acknowledge that birds can perceive the UV range (300-400 $\mathrm{nm}$ ) of a color (Hart et al., 2000), all colors we used reflected low levels UV, and the reflectance differences within the UV spectrum between the colors were small (see Supplementary Materials). Therefore, we consider that UV played a negligible role in our study. When presented on the experimental feeder, both the conspicuous and the nonconspicuous colors were distinguishable from the background such that all prey items were visible, thus preventing camouflagemediated variation in the encounter rate, which can affect the learning rate of birds about the prey. The non-conspicuous colors were similar among each other with respect to the contrast against background. Therefore, by assigning them randomly to the N-CONS and F-CONS treatments, we avoided a possible difference between these treatments due to the effect of prey contrast on learning.

\section{Training of Birds}

On day 3-4, we trained the birds to pull out the prey items on a feeder to eat the sunflower seed beneath each prey. Prior to the training, we deprived each bird of food for $1 \mathrm{~h}$ to motivate foraging. Then, to each bird, we presented an experimental feeder with prey items on which an edible sunflower seed was visibly glued. After the birds learned to pick up a prey item to get the sunflower seed, we presented another experimental feeder with prey items with sunflower seeds glued to the underside of prey. We continued this procedure until all the birds were able to pull out the prey items to get sunflower seeds beneath the prey items. It normally took 1-2 training trials for birds to learn.

Since we used wild birds for testing, we had no priori information about their pre-existing experience with conspicuously colored prey, which may affect the aversive behaviors of the birds (Gamberalle-Stille and Tullberg, 1999). To check and neutralize any pre-existing aversion to specific colors, we used all the eight colors from our color pool (5 non-conspicuous +3 conspicuous) during the training. All birds attacked most of the prey items on the feeder, and we found no observable avoidance behavior against specific colors in all birds (Table S1) except for one bird, which did not attack any of the orange and yellow prey during training. For this bird, we did not use orange and yellow colors to make prey models.

\section{Learning Trials}

For each bird, we allocated one of the three defended prey types (treatment groups: N-CONS, CONS, or F-CONS) and assigned a color chosen randomly from our pool of colors (or one forewing color, and another hindwing color for F-CONS prey) for making the eight identically looking defended prey. Then we assigned three non-conspicuous colors (non-overlapping with the defended prey color) for making the eight undefended prey (4, 2, 2 prey items for each color). Four out of the eight undefended prey in a feeder had a hindwing-imitating part similar to F-CONS prey but of the same non-conspicuous color as their forewing part. The remaining four undefended prey looked like the $\mathrm{N}$-CONS treatment prey: two prey for each remaining nonconspicuous color. In this manner we provided color variability among the eight undefended prey items on a feeder. Through a randomization process, each bird was provided with a different combination of undefended and defended prey colors. Once the colors for defended prey and undefended prey were assigned, the same colors were continuously used throughout the consecutive six trials for each bird.

Before each learning trial, we carefully scrutinized each compartment to remove any alternative sources of food. Then we deprived each bird of food for $1 \mathrm{~h}$ to motivate foraging. For each trial, we put an experimental feeder on the ground of each compartment and recorded each bird's foraging behavior for an hour. We conducted two trials consecutively during each day, and continued this procedure for 3 days (i.e., there were total six learning trials for each bird). We always re-randomized the position of the prey at each trial to avoid positional memory formation about defended prey.

During the testing, we left only one perch near the ground to monitor prey handling and a few perches at higher level (above 1 $\mathrm{m})$ to facilitate normal exploratory behavior of the birds during the trial. All the learning trials were conducted between 1000 and 1600. After finishing the trials each day, we provided food ad libitum to ensure that birds can preserve enough fats in body to endure night-time. We tested 12 birds in each treatment group (N-CONS, F-CONS, and CONS, respectively).

\section{Data Analysis}

For each attacking attempt, we recorded (1) the type of the attacked prey (defended or undefended) and (2) the binary response variable whether each attacked defended prey was rejected or eaten by the bird. We considered that a prey was attacked when a bird pulled out the prey item with its beak, thus revealing the prey's hindwing part if present. We considered a prey item as rejected when the bird did not continue pursuing the prey after an attack without tasting the sunflower seed. In cases when the bird did not reject the prey after pulling out and subsequently tasted the seeds, we considered these as eaten (i.e., attack + not rejected $=$ eaten). Based on this criteria, we extracted one variable for each attacking attempt (binary response whether the attacked prey were rejected or not) and two variables for each learning trial (the number of attacked defended prey and the number eaten defended prey). Then we compared how these variables changed during six consecutive trials.

Most of the attacks toward defended prey were performed within $20 \mathrm{~min}$ (451 out of 464 observations) and we only analyzed the first eight attacks (half of the prey items on each feeder and also the number of defended/undefended prey on each feeder) within this duration to minimize the effect of the change in the relative availability of different prey types due to prey removal by birds.

In most cases, birds pulled out and handled the prey on the feeder or on the lower perch that we set up. However, occasionally a bird took the pulled out prey to higher perches where we could not monitor their behavior through video (157 out of 663 events; see Supplementary Materials). In order to adequately decide 
whether in such a situation the prey were subsequently rejected or not, we quantified behavior of 28 birds and measured the latency from the moment of taking prey to a lower perch to the moment of dropping the prey item. Most of the times the birds spent no longer than $3 \mathrm{~s}$ to reject the prey (95\% in 215 cases of rejecting the prey), while they spent longer time when they accepted and tasted the prey (95\% in 289 cases of accepting and tasting the prey). Therefore, we used $3 \mathrm{~s}$ threshold to decide whether the prey was rejected or eaten by a bird who took the prey to the upper perch (longer than $3 \mathrm{~s}$ indicates that the prey was likely to be accepted). With this threshold, we only run a small risk (of about 5\%) that we are falsely classify the bird behavior on higher perch (see Supplementary Information for more detailed justification). We note here that this estimation of unobserved cases might have affected the results of rejection analysis, but not the initial attacking attempt analysis.

Previous studies on animal learning curves have shown that they do not follow a linear relationship, but, on average, follow a power function, so called "power law of learning" (Newell and Rosenbloom, 1981; Ritter and Schooler, 2001). We adopted the power function for analysis and assumed that avoidance learning process of birds follows simple power law function (response $=$ $a \times$ trial $^{b}$ ) with negative $b$ (thus the response decreases as trials go on). The parameter $b$ determines the learning rate, and the parameter $a$ determines the response at trial $=1$. We calculated and compared the parameter $b$ to test whether the learning rate differed between treatments using linear mixed models in log-log space in which the learning curves are represented in a simple linear form (Ritter and Schooler, 2001). To take into account the variation in learning speed between individual birds and to resolve the problems associated with repeated measurements within each individual, we set $\log$ (trial) to have random slope and intercept within each bird in a way that all coefficients associated with the same random-effect terms are correlated (Bates et al., 2014). We graphically diagnosed the model fit by following the guideline (Bates et al., 2014). For more details on the learning curve and equations, see Supplementary Materials.

We used generalized linear models for comparing the probability of rejection of the attacked prey, analysis of variance for comparing mean attacked/eaten prey within trials, Chisquare test to compare rejection frequencies. $P$-values were adjusted to control the false discovery rate whenever multiple comparison was performed (Benjamini and Hochberg, 1995). Two birds (one in F-CONS and one in CONS group, respectively) were excluded from the analysis since they attacked only a few prey items per trial. Total 193 videos from 34 birds were analyzed. All analyses were conducted in $\mathrm{R}$ ( $\mathrm{R}$ development core team, http://www.r-project.org).

\section{RESULTS}

\section{Changes in the Attack Rates on Prey}

During six consecutive trials, the birds learned to avoid the defended prey before attacking it, but the speed of learning differed among treatment groups [Figure 3A; $\chi_{(2)}^{2}=8.462, p=$ 0.015]. Post-hoc multiple comparisons showed that birds learned to avoid both F-CONS and CONS prey faster than N-CONS prey
(F-CONS vs. N-CONS, $z=-2.459$, $p_{a d j}=0.021$; CONS vs. NCONS, $z=-2.593$, $\left.p_{a d j}=0.021\right)$. We found no difference in the learning speed between F-CONS and CONS prey $(z=-0.160$, $\left.p_{a d j}=0.873\right)$. At the first trial, there were no differences in the number of attacks among treatment groups [gray area in Figure 3A; ANOVA; $F_{(2,30)}=0.138, p=0.872$ ]. However, at the sixth trial, we found significant differences in the attack rates among the treatment groups $\left[F_{(2,25)}=6.842, p=0.004\right]$; both F-CONS and CONS prey were attacked less than N-CONS prey [F-CONS vs. N-CONS, $t_{(1)}=2.732, p_{a d j}=0.017$; CONS vs. $\mathrm{N}$-CONS, $\left.t_{(1)}=3.491, p_{a d j}=0.005\right]$. The number of attacks on F-CONS and on CONS prey did not differ at the sixth trial $\left[t_{(1)}=\right.$ $\left.0.740, P_{a d j}=0.466\right]$.

These results suggest that the presence of post-attack display facilitated predators' associative learning between the nonconspicuous forewing and prey distastefulness, which supports the facilitation hypothesis.

\section{Changes in the Post-attack Rejection of Prey}

Among the prey that have been attacked, the probability of rejection of the prey increased throughout the trials [Figure 3B; $\left.\chi_{(1)}^{2}=19.163, P<0.001\right]$ and the speed of increase differed among the three treatment groups $\left[\chi_{(2)}^{2}=7.267, p=0.026\right]$. The rejection probability increased faster for CONS prey than $\mathrm{N}$-CONS prey $\left(z=2.512, p_{a d j}=0.036\right)$. However, no significant differences were found between F-CONS and N-CONS prey $(z=$ $\left.1.381, p_{a d j}=0.213\right)$ or between F-CONS and CONS prey $(z=$ $\left.1.246, p_{a d j}=0.213\right)$. The rejection probability did not differ among treatment groups at the first trial $\left[\chi_{(2)}^{2}=0.080, p=0.961\right]$ nor at the sixth trial $\left[\chi_{(2)}^{2}=4.329, p=0.115\right]$.

However, frequency analysis of the overall rejection frequencies showed a significant association between treatment groups and rejection frequencies [Figure 3B bottom part; $\left.\chi_{(2)}^{2}=11.889, p=0.003\right]$. Specific comparisons between two groups revealed that F-CONS prey were rejected more often than N-CONS prey [Figure 3B, $\chi_{(1)}^{2}=10.789, p_{a d j}=0.003$ ]. Additionally, F-CONS prey were rejected marginally significantly more often than the CONS prey $\left[\chi_{(1)}^{2}=3.985, p_{a d j}=0.069\right]$. We found no difference between CONS prey and N-CONS prey in overall rejection frequencies $\left[\chi_{(1)}^{2}=0.354, p_{a d j}=0.552\right]$.

Hence, the support for the aposematic signaling hypothesis is equivocal. Overall rejection rates of F-CONS prey were higher than the other two prey types which is congruent with the idea that post-attack conspicuous display dissuaded the predators from further attacks. However, we found no clear evidence that the probability of post-attack rejection increased faster for F-CONS prey than N-CONS prey.

\section{Changes in the Number of Eaten Prey}

The number of finally eaten defended prey decreased through trials and there were significant differences in the speed of decrease among the treatments [Figure 3C; $\chi_{(2)}^{2}=9.738$, $p=0.008$ ]. Post-hoc comparisons revealed that the speed of decrease was faster for both F-CONS and CONS prey than NCONS prey (F-CONS vs. N-CONS, $z=-2.386$, $p_{a d j}=0.026$; 
A

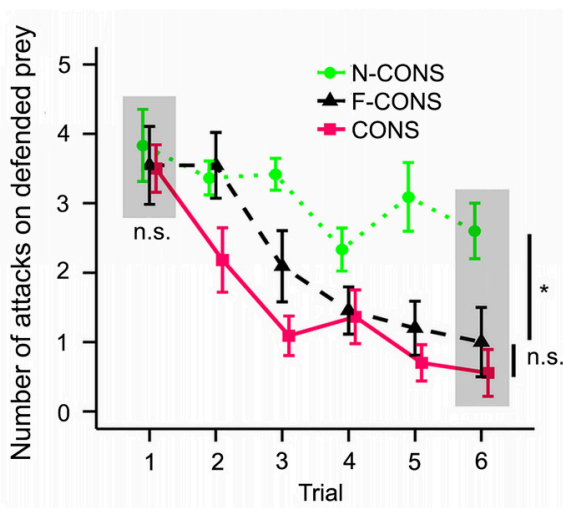

B

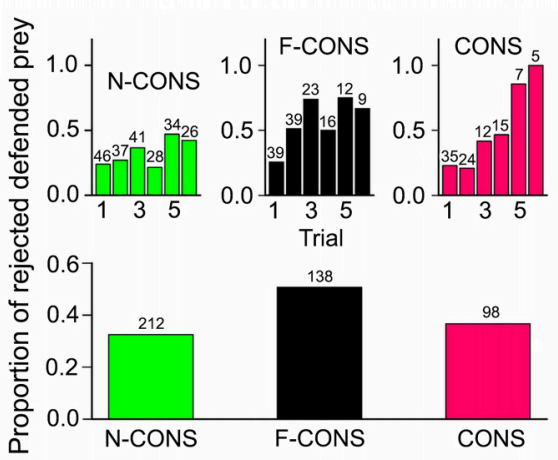

C

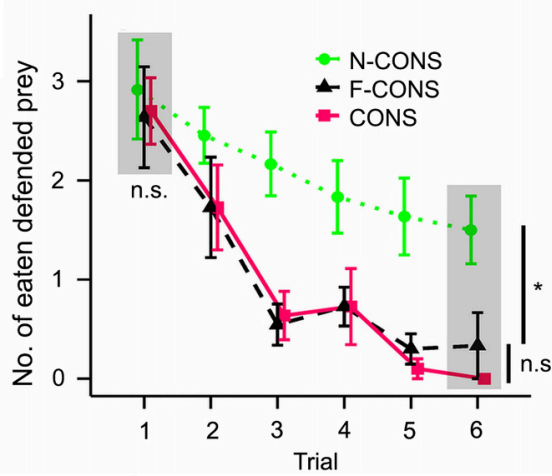

FIGURE 3 | Comparison of the avoidance learning rate of predators in three treatment groups. The treatment groups are non-conspicuous (green dotted lines; $N=12$ birds; $N$-CONS), facultatively conspicuous (black dashed lines; $N=11$; F-CONS), conspicuous (red straight lines; $N=11$; CONS). (A) Initial attacking rate on defended prey for each treatment. (B-top) The frequency of rejection of defended prey among those that have been attacked for each treatment. (B-bottom) The overall frequency of rejection of defended prey among those that have been attacked pooled across trials. The number on each bar represents the number of attacked prey in each trial. (C) The number of eaten (attack + not rejected) defended prey for each treatment. The gray areas and statistics in $\mathbf{( A , C )}$ show the comparison between treatment at the first and at the last (sixth) trial separately. The points and error bars indicate mean \pm standard error of the mean. The symbol n.s. indicates non-significant difference, ${ }^{*} P<0.05$.

CONS vs. N-CONS, $\left.z=2.994, p_{a d j}=0.008\right)$. We found no difference between F-CONS and CONS prey $\left(z=-0.627, p_{a d j}=\right.$ 0.531).
For the first trial only, we found no difference among the treatment groups in the number of eaten prey [gray area in Figure 3C; $\left.F_{(2,30)}=0.105, p=0.901\right]$. On the other hand, at the sixth trial, we found significant differences among treatment groups $\left[F_{(2,25)}=8.060, p=0.002\right]$. Both of F-CONS and CONS prey were eaten less often than N-CONS prey at the sixth trial [F-CONS vs. N-CONS, $t_{(1)}=2.952, p_{a d j}=0.010$; CONS vs. $\mathrm{N}$-CONS, $\left.t_{(1)}=3.795, p_{a d j}=0.003\right]$. We found no difference in the number of eaten prey between F-CONS and CONS prey at the sixth trial $\left[t_{(1)}=0.822, p_{a d j}=0.419\right]$. These results show that F-CONS prey avoided being eaten by predators through predator avoidance learning faster than $\mathrm{N}$-CONS prey, and the speed of the predator learning was nearly as fast as for CONS prey.

\section{DISCUSSION}

The birds learned to avoid attacking facultatively conspicuous prey more quickly than non-conspicuous prey. Hence, the results clearly support the facilitation hypothesis: the postattack conspicuous display by the prey prevented the prey from being attacked by facilitating the predator's learning on the association between the non-conspicuous normal look of the prey and chemical defenses. Our results also suggest that, when detection rates were the same among prey, the speed of avoidance learning was similar between facultatively conspicuous prey and conspicuous prey. This demonstrates that, in terms of facilitating avoidance learning in predators, the facultatively displayed aposematic signal in a prey can be as effective as the typical static aposematic signal.

While we are cautious about the interpretation of the results of aposematic signaling hypothesis because of the unobserved cases, they were expected to affect all treatments in a neutral way and our procedures (in Data Analysis Section) were expected to minimize the associated errors. In our results, we did not find a significant support for the aposematic signaling hypothesis in terms of learning speed. Although the rejection rate increased at the later trials, the speed of increase in rejection rate did not differ significantly between facultatively conspicuous prey and non-conspicuous prey. However, the overall rejection rates were consistent with the hypothesis: while the rejection rate at the first trial was similar between the two treatments $(24 \%$ for non-conspicuous prey, $26 \%$ for facultatively conspicuous prey), it rapidly increased at the second and third trial for facultatively conspicuous prey and maintained the higher rate throughout all six trials compared to those of non-conspicuous prey (Figure 3B, upper panel). In a pooled analysis of rejection rate, the probability of prey rejection was about 1.5 times higher in facultatively conspicuous prey than non-conspicuous prey. This suggests that, the facultatively conspicuous prey had more chances to avoid further handling than had the non-conspicuous prey, which consequently decreased the final consumption rate by predators.

In this study, our prey model was specifically designed for post-attack display and did not induce startling responses of birds (Ingalls, 1993; Oloffson et al., 2012; Figure 3B upper panel; the rejection rates were similar between treatments at the initial trials). However, many post-attack aposematic displays 
often come with sudden movements (i.e., deimatic display; Umbers et al., 2015) which should elicit additional psychological effects on predators. Based on the literatures on startle response (Ingalls, 1993; Öhman and Mineka, 2001), we anticipate that startling elements may elicit two additional psychological effects on predators during post-attack events and avoidance learning processes: (1) the startling elements may increase the initial rejection rates against naive predators and decrease the risk of initial predation when predator learning has not occurred yet, and (2) the salience of startling elements may reinforce the association between the post-attack display and unpalatability (for predators that handle the prey despite startling displays), thus promoting the rejection of prey at the post-attack stages of encounters. We encourage further experiments on the postattack display with startling elements to fully determine whether the aposematic signaling mechanism contributes to the evolution of the post-attack display in defended species.

Facilitation function in learning to avoid visual aposematic signals by predators is known for non-visual stimuli such like taste, smell, or sound (Rowe and Halpin, 2013). For example, it has been suggested that an additional signal in nonvisual modality, such like sound, scent, or taste simultaneously presented with the aposematic visual signal, strengthens the predator's learning of the association between unpalatability and the visual warning signal (Rowe, 2002; Lindström et al., 2006; Siddal and Marples, 2008). Our results suggest that similar facilitation of learning may also occur between two separate visual cues: subsequent presentation of a conspicuous color facilitated the association between unpalatability and the initially presented less conspicuous color.

What could be the relevance of this experimental study to understanding of the evolutionary processes in natural conditions? We showed under laboratory conditions that the prey with facultatively displayed warning signals can gain survival benefits by facilitating avoidance learning. Therefore, this facilitation mechanism is likely to play a role in the evolution of post-attack displays resulting in unpalatable prey to dynamically display warning signals at the moment of being attacked while minimizing the probability of being detected. However, before extending our laboratory results to a natural situation, a few issues should be considered.

First, the prey may benefit from the post-attack display's learning facilitation function only if the initial handling by the predator rarely leads to prey's death while it informs the predators about prey chemical defense. Careful observations of birds handling defended prey indeed revealed that the prey is rarely killed and often not even seriously injured (Sillen-Tullberg, 1985).

Second, there exists a possibility that our results have overestimated the role of the facilitation effect in natural environments. While all prey types were undoubtedly easily detectable in our experimental situation, the detection rate of facultatively aposematic insects in their normal condition may be lower due to their camouflage against natural backgrounds. The low detection rate may decrease the speed of learning (and facilitate forgetting) by predators in comparison to the learning speed observed in our experiments, making facultative aposematism less efficient in terms of learning. However, the low detection risk brings benefits to the prey because it lowers detection risk by predators that are not susceptible to the prey defenses. This suggests that a chemically defended prey is likely to evolve facultative post-attack aposematic displays when avoidance of detection is important while at the same time the facilitation effect in avoidance learning by predators is also important for prey survival.

Finally, because we tested only the experienced wild-caught birds, it is possible that the facilitated avoidance learning against conspicuous color was observed simply due to the birds' prior experience with aposematic prey. In other words, because experienced predators might be already wary of typical aposematic colors, this wariness might have facilitated the observed faster avoidance learning in our experiment, and that naïve birds will not show such a facilitation effect. This difference in learning mechanisms are similar to the two distinctive psychological mechanisms, potentiation and augmentation (Rusiniak et al., 1979; Batsell et al., 2001; see Supplementary Materials for further explanations on these terms). An experiment that compares the learning speed between naïve and experienced birds would reveal the specific mechanism(s). Having said that, we still argue that naive predators are present only for a short period of time in nature (e.g., naïve fledgling birds quickly become experienced after several encounters with aposematic insects; Svádová et al., 2009). Hence, we believe that our experiments were performed on the type predators that are present in nature all year around and are the main agents of natural selection on post-attack aposematic display in insect prey.

In summary, this is the first study to show that post-attack display of aposematic signals facilitate avoidance learning in predators by enhancing the association between the "normal" relatively non-conspicuous features of the prey and the presence of chemical defenses. Our results highlight the possibility that similar facilitation mechanisms may contribute to the evolution of various forms of post-attack displays that are revealed upon prey capture in defended arthropods (e.g., Kang et al., 2011; Umbers and Mappes, 2015) as well as in vertebrates (e.g., Davis, 1948; Lenzi-Mattos et al., 2005). We suggest that future studies determine how various features of the post-attack displays, and the properties of the "normal" pre-attack morphology, affect the two mechanisms of unpalatable insects' defenses: aposematic post-attack signaling and facilitation of learning mechanisms.

\section{AUTHOR CONTRIBUTIONS}

CK, SL, PJ conceived and designed the project. CK, HC collected data, CK, PJ analyzed the data, CK wrote the first draft of the manuscript, all authors contributed to the revisions.

\section{FUNDING}

This study was supported by National Research Foundation of Korea (grants: NRF-2010-0025546, NRF2013R1A2A2A01006394) and BK-21 program awarded to the 
School of Biological Sciences, Seoul National University. CK was supported by NRF (2014R1A6A3A03053952) and Natural Sciences and Engineering Research Council of Canada Discovery Accelerator Supplements Program (NSERC DAS).

\section{ACKNOWLEDGMENTS}

We sincerely thank to B. S. Jang, D. R. No, W. Y. Lee, I. K. Hwang, J. W. Lee for their invaluable assistance while conducting the

\section{REFERENCES}

Aronsson, M., and Gamberale-Stille, G. (2009). Importance of internal pattern contrast and contrast against the background in aposematic signals. Behav. Ecol. 20, 1356-1362. doi: 10.1093/beheco/arp141

Barnett, C. A., Skelhorn, J., Bateson, M., and Rowe, C. (2012). Educated predators make strategic decisions to eat defended prey according to their toxin content. Behav. Ecol. 23, 418-424. doi: 10.1093/beheco/arr206

Bates, D., Mächler, M., Bolker, B., and Walker, S. (2014). Fitting linear mixedeffects models using lme4. J. Stat. Softw. 67, 1-48. doi: 10.18637/jss.v067.i01

Batsell, W. R. Jr., Paschall, G. Y., Gleason, D. I., and Batson, J. D. (2001). Taste preconditioning augments odor-aversion learning. J. Exp. Psychol. Anim. Behav. 27, 30-47. doi: 10.1037/0097-7403.27.1.30

Benjamini, Y., and Hochberg, Y. (1995). Controlling the false discovery rate: a practical and powerful approach to multiple testing. J. Roy. Stat. Soc. B. Methodol. 57, 289-300.

Brodie, E. D. III, and Brodie, E. D. Jr. (1999). Predator-prey arms races Asymmetrical selection on predators and prey may be reduced when prey are dangerous. Bioscience 49, 557-568. doi: 10.2307/1313476

Davis, D. D. (1948). Flash display of aposematic colors in Farancia and other snakes. Copeia 1948, 208-211. doi: 10.2307/1438456

Endler, J. A., and Mappes, J. (2004). Predator mixes and the conspicuousness of aposematic signals. Am. Nat. 163, 532-547. doi: 10.1086/382662

Exnerová, A., Landová, E., Štys, P., Fuchs, R., Prokopová, M., and Cehláriková, P. (2003). Reactions of passerine birds to aposematic and non-aposematic firebugs (Pyrrhocoris apterus; Heteroptera). Biol. J. Linn. Soc. 78, 517-525. doi: 10.1046/j.0024-4066.2002.00161.x

Exnerová, A., Svádová, K. H., Fučíková, E., Drent, P., and Štys, P. (2010). Personality matters: individual variation in reactions of naive bird predators to aposematic prey. Proc. R. Soc. B Biol. Sci. 277, 723-728. doi: $10.1098 / \mathrm{rspb} .2009 .1673$

Gamberale-Stille, G. (2001). Benefit by contrast: an experiment with live aposematic prey. Behav. Ecol. 12, 768-772. doi: 10.1093/beheco/12.6.768

Gaberale-Stille, G., and Guilford, T. (2003). Contrast versus colour in aposematic signals. Anim. Behav. 65, 1021-1026. doi: 10.1006/anbe.2003.2098

Gamberalle-Stille, G., and Tullberg, B. (1999). Experienced chicks show biased avoidance of stronger signals: an experiment with natural colour variation in live aposematic prey. Evol. Ecol. 13, 579-789. doi: 10.1023/A:1006741626575

Gittleman, J. L., and Harvey, P. H. (1980). Why are distasteful prey not cryptic? Nature 286, 149-150. doi: 10.1038/286149a0

Hart, N. S., Patridge, J. C., Cuthill, I. C., and Bennett, A. T. D. (2000). Visual pigments, oil droplets, ocular media and cone photoreceptor distribution in two species of passerine bird: the blue tit (Parus caeruleus L.) and the blackbird (Turdus merula L.). J. Comp. Physiol. A 186, 375-387. doi: $10.1007 /$ s003590050437

Kang, C., Lee, S.-I., and Jablonski, P. G. (2011). Effect of sex and bright coloration on survival and predator-induced wing damage in an aposematic lantern fly with startle display. Ecol. Entomol. 36, 709-716. doi: 10.1111/j.13652311.2011.01319.x

Ingalls, V. (1993). Startle and habituation responses of blue jays (Cyanocitta cristata) in a laboratory simulation of anti-predator defenses of Catocala moths (lepidoptera: Noctuidae). Behaviour 126, 77-95. doi: $10.1163 / 156853993 X 00353$ experiments and analyzing videos. We also appreciate to Bruce Waldman and Sami Merilatia for their helpful comments to the manuscript.

\section{SUPPLEMENTARY MATERIAL}

The Supplementary Material for this article can be found online at: http://journal.frontiersin.org/article/10.3389/fevo. 2016.00035
Lenzi-Mattos, R., Antoniazzi, M. M., Haddad, C. F. B., Tambourgi, D. V., Rodrigues, M. T., and Jared, C. (2005). The inguinal macroglands of the frog Physalaemus nattereri (Leptodactylidae): structure, toxic secretion and relationship with deimatic behaviour. J. Zool. 266, 385-394. doi: $10.1017 /$ S095283690500703X

Lindström, L., Lyytinen, A., Mappes, J., and Ojala, K. (2006). Relative importance of taste and visual appearance for predator education in Mullerian mimicry. Anim. Behav. 72, 323-333. doi: 10.1016/j.anbehav.2005. 10.015

Mackintosh, N. J. (1983). Conditioning and Associative Learning. New York, NY: Oxford University Press.

Mappes, J., and Alatalo, R. V. (1997). Effects of novelty and gregariousness in survival of aposematic prey. Behav. Ecol. 8, 174-177. doi: 10.1093/beheco/8.2.174

Mappes, J., Marples, N., and Endler, J. A. (2005). The complex business of survival by aposematism. Trends. Ecol. Evol. 20, 598-603. doi: 10.1016/j.tree.2005. 07.011

Marples, N. M., Ropers, T. J., and Harper, D. G. C. (1998). Responses to wild birds to novel prey: evidence of dietary conservatism. Oikos 83, 161-165. doi: $10.2307 / 3546557$

Merilaita, S., and Ruxton, G. D. (2007). Aposematic signals and the relationship between conspicuousness and distinctiveness. J. Theor. Biol. 245, 268-272. doi: 10.1016/j.jtbi.2006.10.022

Newell, A., and Rosenbloom, P. S. (1981). "Mechanisms of skill acquisition and the law of practice," in Cognitive Skills and Their Acquisition, ed. J. R. Anderson (Hillsdale, NJ: Lawrence Erlbaum Associates), 1-55

Nickle, D. A., and Castner, J. L. (1995). Strategies utilized by katydids (Orthoptera: Tettigonidae) against diurnal predators in rainforests of northeastern. J. Orthoptera Res. 4, 75-99. doi: 10.2307/3503461

Öhman, A., and Mineka, S. (2001). Fears, phobias, and preparedness: towards an evolved module of fear and fear learning. Psychol. Rev. 108, 483-522. doi: 10.1037/0033-295X.108.3.483

Oloffson, M., Eriksson, S., Jakobsson, S., and Wiklund, C. (2012). Deimatic display in the European Swallowtail Butterfly as a secondary defence against attacks from great tits. PLoS ONE 7:e47092. doi: 10.1371/journal.pone.0047092

Osorio, D., Jones, C. D., and Vorobyev, M. (1999). Accurate memory for colour but not pattern contrast in chicks. Curr. Biol. 9, 199-202. doi: 10.1016/S09609822(99)80089-X

Ritter, F. E., and Schooler, L. J. (2001). “The learning curve," in International Encyclopedia of the Social \& Behavioral Sciences, eds N. J. Smelser and P. B. Baltes (Oxford, UK: Elsevier Science), 8602-8605. doi: 10.1016/B0-08-0430767/01480-7

Rowe, C. (2002). Sound improves visual discrimination learning in avian predators. Proc. Biol. Sci. 269, 1353-1357. doi: 10.1098/rspb.20 02.2012

Rowe, C., and Halpin, C. (2013). Why are warning displays multimodal? Behav. Ecol. Sociobiol. 67, 1-15. doi: 10.1007/s00265-013-1515-8

Rusiniak, K. W., Hankins, W. G., Garcia, J., and Brett, L. P. (1979). Flavor-illness aversions: potentiation of odor by taste in rats. Behav. Neural. Biol. 25, 1-17. doi: 10.1016/S0163-1047(79)90688-5

Ruxton, G. D., Sherratt, T. N., and Speed, M. P. (2004). Avoiding Attack: The Evolutionary Ecology of Crypsis, Warning Signals and Mimicry. New York, NY: Oxford University Press. 
Siddal, E. C., and Marples, N. M. (2008). Better to be bimodal: the interaction of color and odor on learning and memory. Behav. Ecol. 19, 425-432, doi: 10.1093/beheco/arm155

Sillen-Tullberg, B. (1985). Higher survival of an aposematic than of a cryptic form of a distasteful bug. Oecologia 67, 411-415. doi: 10.1007/BF00384948

Skelhorn, J., and Rowe, C. (2007). Predators' toxin burdens influence their strategic decisions to eat toxic prey. Curr. Biol. 17, 1479-1483. doi: 10.1016/j.cub.2007.07.064

Stevens, M., and Ruxton, G. D. (2012). Linking the evolution and form of warning coloration in nature. Proc. R. Soc. B Biol. Sci. 279, 417-426. doi: 10.1098/rspb.2011.1932

Svádová, K., Exnerová, A., Štys, P., Landová, E., Valenta, J., Fučíková, A., et al. (2009). Role of different colours of aposematic insects in learning, memory and generalization of naïve bird predators. Anim. Behav. 77, 327-336. doi: 10.1016/j.anbehav.2008.09.034

Umbers, K. D. L., Lehtonen, J., and Mappes, J. (2015). Deimatic displays. Curr. Biol. 25, R58. doi: 10.1016/j.cub.2014.11.011
Umbers, K. D. L., and Mappes, J. (2015). Postattack deimatic display in the mountain katydid, Acripeza reticulate. Anim. Behav. 100, 68-75. doi: 10.1016/j.anbehav.2014.11.009

Urcelay, G. P., and Miller, R. R. (2009). Potentiation and overshadowing in pavlovian fear conditioning. J. Exp. Psychol. Anim. Behav. Process. 35, 340-356. doi: $10.1037 / \mathrm{a} 0014350$

Conflict of Interest Statement: The authors declare that the research was conducted in the absence of any commercial or financial relationships that could be construed as a potential conflict of interest.

Copyright (c) 2016 Kang, Cho, Lee and Jablonski. This is an open-access article distributed under the terms of the Creative Commons Attribution License (CC BY). The use, distribution or reproduction in other forums is permitted, provided the original author(s) or licensor are credited and that the original publication in this journal is cited, in accordance with accepted academic practice. No use, distribution or reproduction is permitted which does not comply with these terms. 